\title{
United Nations releases draft strategy for noncommunicable diseases
}

$\mathrm{B}$ road recommendations aimed at encouraging "whole-of-society" efforts, strengthening national policies, reducing risk factors, increasing international cooperation and improving research and monitoring lie at the core of a draft United Nations (UN) plan to prevent and control noncommunicable diseases (NCDs).

The draft "outcome document" will be the basis for the high-level UN summit on noncommunicable diseases to be held in New York City, New York, from September 19-20, which many health experts hope will be a turning point in the fight against illnesses that annually kill tens of millions of people around the world.

"I have been working on NCDs for decades, and what is happening this year is very exciting. It's unprecedented," says Dr. Puska Pekka, director general of the National Institute for Health and Welfare in Helsinki, Finland. "For the first time, NCDs are becoming high on the global political agenda."

A UN report says 36 million people died from noncommunicable diseases such as cardiovascular diseases, cancers, chronic respiratory diseases and diabetes in 2008 (www.who.int/nmh /events/2011/introduction_doc.pdf). Even worse, NCDs are rising rapidly, particularly in developing nations. By 2030, the report states, the number of annual deaths from noncommunicable diseases is projected to reach 52 million, exceeding deaths attributed to communicable, maternal, perinatal and nutritional diseases.

The draft document is "fairly neutral" but will provide a good basis for real political discussion, says Pekka. He hopes, however, that meeting participants will also discuss why such a small portion of global health funding goes toward preventing and controlling diseases that kill so many people.

"There is a big, big mismatch, and they should say something about that,"

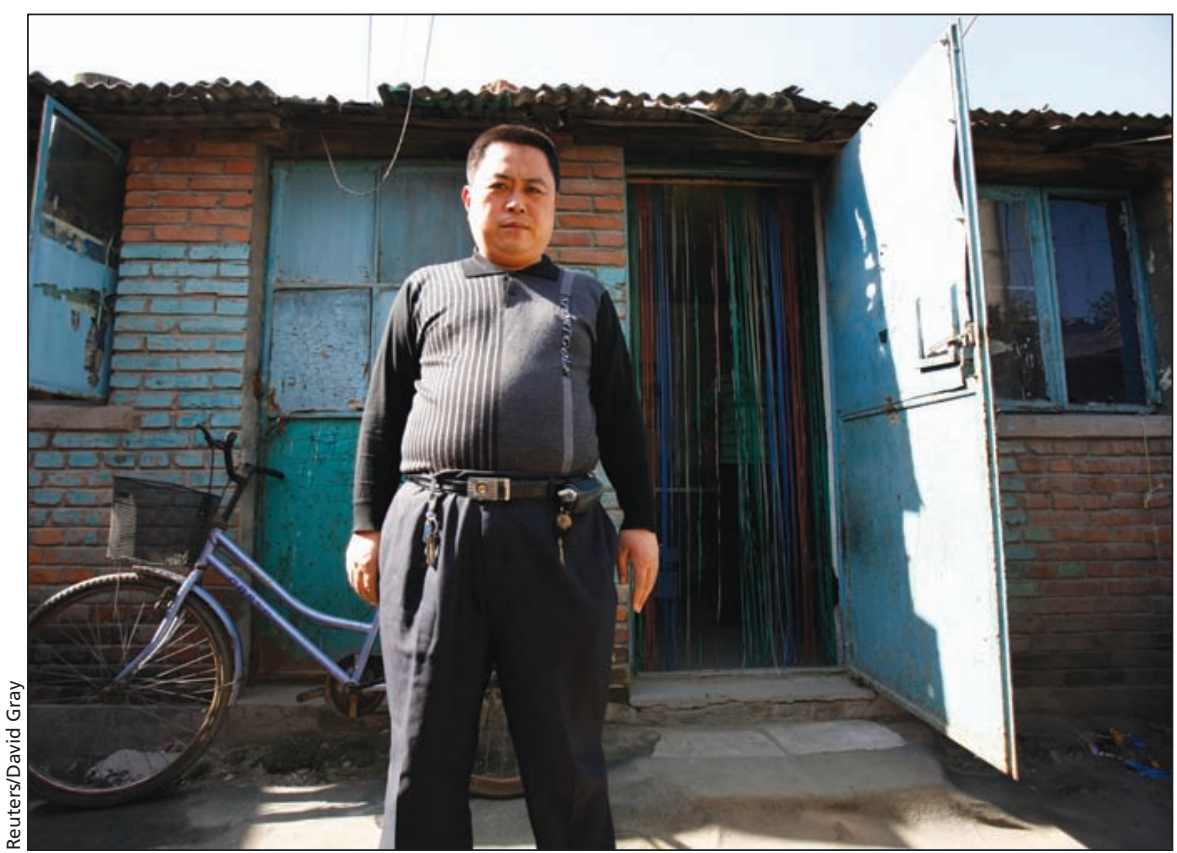

The government of China has estimated that as many as $\mathbf{8 0}$ million people in the country could be killed over the coming decade as a result of a surge in chronic diseases such as diabetes brought on by changing lifestyles.

says Pekka, who from 2001-2003 served as director of NCD prevention and health promotion for the World Health Organization (WHO).

Traditionally, the majority of funds donated to developing nations by their richer cousins have been earmarked to fight infectious diseases such as tuberculosis, HIV/AIDS and malaria. The reason Western countries have largely been passive in fighting NCDs remains "a bit of a mystery," suggests Pekka. Perhaps richer nations are acting in their own interests, he says, tackling infectious diseases in other lands to prevent them from reaching their own borders.

"There are a number of possibilities," says Pekka. "Another is that there is still a wrong picture of people in the developing world — that they all live in the jungle and only infectious diseases are a problem."

The global neglect of NCDs is particularly frustrating to some health experts because the risk factors are so well known - smoking, poor diet, lack of physical activity, alcohol abuse - and effective solutions exist. "Much of this devastating loss of human life can be avoided at relatively low costs," says David Stuckler, a lecturer in sociology at the University of Cambridge in the United Kingdom. "We know which costeffective measures can work. We have a political problem of getting them started.'

There are several possible reasons why politicians have been slow to engage in the fight against noncommunicable diseases. One is opposition to certain measures to reduce risk factors from large, multinational corporations. Policies to dramatically reduce sugar or salt intake, for example, are not often popular with food companies that make sugary beverages and salty snacks. Efforts to reduce smoking, particularly in growing markets in developing nations, rarely sit well with tobacco companies. 
Another possible reason that NCDs have traditionally received little political attention is that they don't invoke the same level of fear in the public as an influenza outbreak or the spread of HIV or some other infectious disease. Then there is the commonly held belief that many people prone to NCDs, such as the obese, have only themselves to blame.

"There is this idea that people who are obese are agents of their own misfortune, but that saps and undermines the potential of effective public health policies," says Stuckler. "We have to reframe the debate and realize we are all in this together and anyone can be affected at any stage in their life."

The UN high-level meeting will provide an excellent opportunity to draw much-needed global attention to the health burden of NCDs, says Stuckler. But the current version of the meeting's draft outcome document, he notes, is missing one crucial component. "The concern with the current document is that it is not as strong as it could be on accountability. This is a common problem with UN documents. Where are the teeth?"

The lack of specific targets in the document was also criticized by the NCD Alliance, which consists of four international groups that represent the four main NCDs: cardiovascular disease, diabetes, cancer, and chronic respiratory disease. "This omission is a critical weakness of the [draft], and one that civil society is united around and will support Member States to rectify," states the alliance's response to the draft outcomes document (www.ncdalliance .org/sites/default/files/rfiles/Priority $\% 20$ Language $\% 20$ for $\% 20$ the $\% 20$ Outcomes \%20Document\%204\%20July\%202011 .pdf). "Bold, specific, and measurable targets and timetables (both short-term and long-term) are integral to creating a shared vision between Member States and civil society, driving international and national follow-up action, and catalyzing more effective use and coordination of resources."

Other priorities that should be addressed in New York were outlined in a recent paper, to which Stuckler and many other NCD experts contributed, that described the upcoming UN meeting as an "unrivalled opportunity to create a sustained rights-based global movement to tackle NCDs" that could have an effect similar in magnitude to the UN General Assembly Special Session on HIV infection and AIDS held a decade ago (Lancet 2011;377:143847). The paper proposes five cost-effective priority interventions to abate the harm caused by NCDs: accelerate implementation of the WHO's Framework Convention on Tobacco Control; mass-media campaigns and food industry action to reduce salt consumption; policies to promote physical activity and diets low in saturated and trans fats, salt and sugar; policies to decrease harmful alcohol intake through price increases, advertising bans and restricted access; and universal access to affordable drugs to treat NCDs.
It is also important that the people attending the UN meeting be realistic about the goals they set and be cognizant of how difficult it can be to create policies that actually steer people toward healthier lifestyles, says Derek Yach, director of global-health policy for PepsiCo, citing regulations to reduce salt consumption as an example.

"Policy statements that claim salt reduction is a 'simple' intervention are wrong. Dietary change takes deep insight into consumer behavior, meticulous attention to taste and related sensory preferences combined with optimal pricing across the supply chain. It requires that industry incentives and metrics align with long-term goals and that governments strongly support required changes. Further, it requires appreciation that consumers' wants and needs differ significantly from one region to another. This complexity is rarely addressed in public policy statements," Yach, a former representative of the director general at the WHO, writes in an email.

"The upcoming [UN high-level meeting] is a once in a generation chance to chart a way forward to address major looming threats to health," Yach adds. "We need to challenge whether the approaches taken to address the nutritional aspects of NCDs, especially in developing countries, will have the desired impact." - Roger Collier, CMAJ

CMAJ 2011. DOI:10.1503/cmaj.109-3951 